\title{
Epidemiological Sociology (Part Two): "Sociology of Epidemiology". The Sociology Applied to the Analysis of Epidemiology
}

\section{Turabian JL*}

Specialist in Family and Community Medicine, Health Center Santa Maria de Benquerencia. Regional Health Service of Castilla la Mancha (SESCAM), Toledo, Spain

*Corresponding author: Jose Luis Turabian, Health Center Santa Maria de Benquerencia Toledo, Spain, Email: jturabianf@hotmail.com

\section{Review Article}

Volume 3 Issue 2

Received Date: August 14, 2019

Published Date: October 17, 2019

DOI: $10.23880 /$ eij-16000128

\section{Abstract}

Epidemiology can benefit by allowing it to be the object of analysis of sociology ("sociology of epidemiology"). The institution of epidemiology shapes the motives, passions and social relationships of scientists. To understand the meaning and structure of the epidemiological experience, it must be framed in the history of the institutions in which its organizing efforts have been manifested. The epidemiological study of the epidemics (smallpox, along with measles, typhus, leprosy or yellow fever) influenced the power relations between the dominant minority and the dominated majority. The epidemiological and medical elite (obviously in relation to the rulers) were the ones who determined the official response to the disease. Epidemiological measures taken during an epidemic posed more threats to the expectations of ordinary people than the epidemic itself. Since the beginning of the 20th century, epidemiology has been an instrument designed to allow white races to inhabit and exploit all areas of the earth. His basis was in social Darwinism. Diseases (epidemics and non-communicable chronic diseases and so-called risk factors) were not studied epidemiologically in different cultural, temporal and spatial contexts. In summary, the disease has been at the service of the dominant power; The arguments of epidemiology must be qualified by sociological evidence.

Keywords: Sociology; Socialization; Epidemiology; Sociology, Framework; Public Health; Political Motivation; Social Influence; Social Power; Policy; Power Relations.

\section{Introduction}

Epidemiology, as defined by the WHO (2015), is "the study of the distribution and determinants of healthrelated states or events, including disease, and the application of this study to the control of diseases and other health problems." The epidemiologists strive to describe, explain, predict and control disease [1].

Epidemiology is the branch of public health that aims to describe and explain the dynamics of population health, identify the elements that comprise it and understand the forces that govern it, in order to 
intervene in the course of its natural development. Currently, it is accepted that in order to fulfil its mission, epidemiology investigates the distribution, frequency and determinants of health conditions in human populations, as well as the modalities and impact of the social responses established to address them [2].

Sociology and epidemiology have an uneasy relationship. The epidemiologists find sociology helpful for describing and analyzing epidemiological issues, but they are less enthusiastic when la epidemiology becomes the subject of sociological scrutiny [3].

However, sociological roles imply the articulation of social causality in the epidemiological study of health ("sociology in epidemiology"), together with the articulation within the sociology of the importance of the study of epidemiology ("sociology of epidemiology") [4]. The sociological approaches on the epidemiology as a study' object (Figure 1) can allow to answer to numerous interesting sociological questions ("sociology of epidemiology") [3].

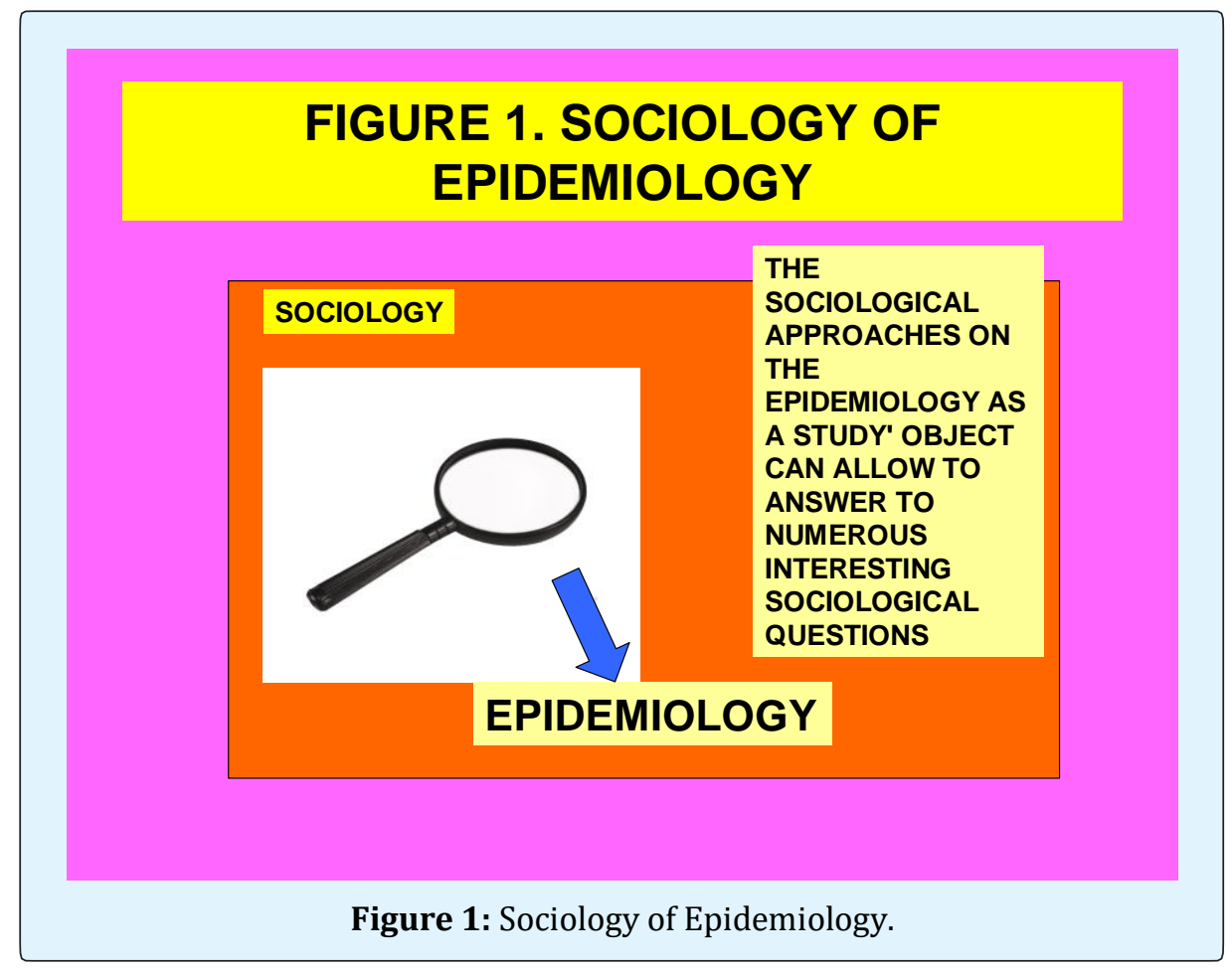

There is a big difference between "sociology in epidemiology" and "sociology of epidemiology", although only initially. If consistent, sociology in epidemiology should become sociology of epidemiology. The key is to understand how the application and use of epidemiology are related to each other and to the larger social forces, and how they offer limitations and opportunities. The theoretical tools of sociology can help unravel the complex challenges faced by policymakers and researchers regarding the connections between society, epidemiological studies, epidemiological decisions, and systems of care. Therefore, it is necessary to frame these issues in a sociological perspective [5].

The concept of health / disease does not exist in fact. The concepts are not there, independent of human beings and history, waiting to be discovered: A concept of health is always linked to an articulated theory, to a historical period, to a society always complex in its configuration. Medical and epidemiological science has historically not been a neutral task, but rather an activity that is especially sensitive to the environment in which it was carried out, and integrated into the culture of the social groups that practiced and / or performed it [6].

It cannot be really understand how people react to illness or other misfortune without an understanding of the type of culture that they have grow up in, or acquired; that is, the lens through which they are perceiving and interpreting their world [7].

The development of health is not an individual problem, but a condition and consequence of social action, but which, in turn, has an individual response that depends on the type of affection, the personality and the functioning of social mediations before the disease. 
In this sense, the "sociology of epidemiology" forces the discussion of the practical application of epidemiology to the sphere of health. Thus, sociology helps the production of knowledge by incorporating the methods and techniques of social research that address mankind in its entirety and help identify problems and alternative solutions from the perspective of the populations involved in these problems.

Methodology of natural scientific research is widely disseminated in the field of research to determine the amount of a health problem in terms of prevalence, incidence, morbidity and mortality. To the extent that the work of health professionals expands its range of action, can include, the question of why a certain epidemiological decision was made, and be answered in sociological terms.

This approach to sociological research is basically qualitative, where rather than predict or measure the phenomenon interpret the reason for the occurrence of this phenomenon within certain trends, social and historical conditions and their consequences on health. The qualitative methods to answer these research questions are very different from those of clinical or epidemiological research, which have been much more conservative about their methods in health research, citing lack of objectivity in qualitative research. However, the art of research is more than the perspective of neutrality and objectivity: it is a multicultural process that requires a method of interpretation that constitutes an essential element of health research and health services [8].

The sociological view of epidemiological work leads us to explore the historical context of production of classical epidemiological knowledge, with the aim of highlighting the notions that contributed to "modelling the content of its practice", and may raise criticisms of the individual-based etiological model, because it condenses the assumptions with which this discipline incorporates the social issue [9].

In this scenario, this article, aims to reflect on the use of sociology to answer epidemiological questions, and more specifically, to use of the methodology of the sociology for analyzing the discipline of epidemiology ("sociology of epidemiology"), and to see how, the arguments of epidemiology, can be modified or qualified by sociological evidences.

\section{Discussion}

Although the transformation of epidemiology into a science has taken several centuries, and can be said to be still a young science, the study of diseases as population phenomena is almost as old as writing, and the first descriptions of conditions that affect whole populations refer to diseases of an infectious nature. The papyrus of Ebers, which mentions pestilent fevers (probably malaria) that ravaged the population of the banks of the Nile around $2000 \mathrm{BC}$, is probably the text in which the oldest reference to a collective suffering is made. The periodic appearance of pests and pestilences in prehistory is indisputable. In Egypt, 3,000 years ago, a goddess of the plague called Sekmeth was worshiped, and there are mummies between two thousand and three thousand years old that show skin conditions suggestive of smallpox and leprosy. Given that mummification was reserved for the most important characters of ancient Egypt -who remained relatively isolated from the people-, it would not be strange that this type of affections was much more frequent among the general population [2].

One of the most notable characteristics of these descriptions is that they make it very clear that the majority of the population firmly believed that many diseases were contagious, unlike the doctors of the time - the precursors of current epidemiologists - who paid scant attention to the disease contagion concept. Preventive actions and control of contagious diseases are also referred to in many old texts. The Bible, the Koran, the Talmud and various Chinese and Hindu books recommend numerous preventive health practices, such as washing hands and food, circumcision, the isolation of the sick and the burial or cremation of corpses. Through the Gospels we know that some patients -like lepers- were invariably isolated and were forbidden to communicate with the healthy population [8].

Sociology reminds epidemiology that there are powerful relationships between science, technology and society. In this sense, Thomas Kuhn shows the history of science as an action of scientific communities in a social and cultural context that share a consensual set of knowledge, methods and values $[10,11]$. Social structures are based on hierarchies and power, which define specific roles of action on stratified positions that allow punishing or rewarding, as well as governing a system of dissemination of information that allows or restricts the action of social actors. In this way, given socio-political conditions, these conflict allow the development of scientific disciplines, including epidemiology, and the application of their knowledge in the instrumentality of solving problems in society. Therefore, from the sociological perspective, epidemiology, as a scientific discipline, is a social institution structured on norms that characterize the behavior of epidemiologists in the exercise of their profession; the institution of epidemiology shapes the motives, passions and social relationships of epidemiologists [12]. 


\section{Epidemiology International Journal}

In order to understand the meaning and structure of clinical and epidemiological experience, it is necessary to fit them into the history of the institutions in which their organizing efforts have been manifested. From the eighteenth century onwards, in order to make clinical and epidemiologic experience possible as a form of knowledge, a reorganization of the hospital field, a new definition of the status of the patient in society and the establishment of a certain relationship between care and experience, were necessary. It was also necessary to open the language to a whole new domain: that of a perpetual correlation between the clinical and the anatomopathological [13].

From the oldest societies, public health/epidemiology was a space of control and surveillance for people and communities; and it is, in the capitalist society where those mechanisms are deepened as Foucault proposes [13]

Since time immemorial of humanity, norms and actions about the cure and prevention of diseases and death, which we now know as public health/epidemiology, were impositions on people, some transformed into life forms, transmitted from generation to generation by the family and the social institutions existing in each historical moment. But these actions were always forms of bio-power and biopolitics, because they were plans to control, monitor and submit, through the norms established in different civilizations, to individuals and the whole community.

Foucault, points out a series of questions linked to the very life of people, which serve as an argument for the application of new control and surveillance technologies. These questions are raised and reflected as collective events, and treated in statistical terms, among them the demography, fertility, births, mortality, and morbidity, and with it also the control of physical, biological, social, and cultural risks, in order to place exclusions or inclusions in medical-epidemiological terms, in a kind of overlapping racism, disaggregated by separation the groups according to level of risk and geographically locating areas of precariousness and abandonment $[13,14]$.

For our approach, modern medicine and epidemiology begins with the work of the Prussian scientist Robert Koch (1843-1910), who discovered the causative agent of tuberculosis and cholera [15]. His radical ideas modified the scientific truths of the previous tradition, which held that most diseases were caused by "miasmas," not by living organisms. Between $1900-1930$ there is the full medicalization of the West, and from the struggles for Africa, China, and the American conquest of the Spanish empire of the Caribbean and the Pacific arises the new discipline of tropical medicine, which since its inception was an imperial instrument destined to enable the white races to inhabit and exploit all areas of the earth. Its basis was social Darwinism: Europeans were at the top of the evolutionary chain and had the right to dominate the rest of humanity. That is, at that time, these statements had the backing of science [16-19].

The discovery of the microbial causes of infectious diseases in the late nineteenth century, and the development of biological technical solutions, placed the axis of epidemiological objectives in infectious diseases. Consequently, the epidemiology developed between 1890 and 1950 basically around these conditions, which is expressed in the fact that the first epidemiology manuals, made 1931, only refer to this type of diseases. This location, with the bacteriological orientation, marked the development of epidemiology by increasingly reducing its objectives to the search for the determining factors and solutions within the biological field. Moreover, given this trend, the further application of epidemiology to chronic diseases, "violence" and addictions, will not substantially modify their conceptions, at least until recently [20].

Economic development was subsequently a decisive driving force in the modern world based on raw materials that could be converted into products, labour for that conversion, credit institutions, and consumers. One of the unintended consequences of the development was the creation of pestilence networks. A catastrophic example was the case of smallpox, along with measles and typhus, which affected all regions of the New World invaded by Europeans, and which completely transformed the ethnic composition of the New World [21].

In any case, whether in Europe or in the New World, the transformation of development caused an epidemic to influence power relations between the dominant minority and the dominated majority. The epidemiological and medical elite (obviously in relation to the rulers) were the ones who determined the official response to the disease. Epidemiologists argued that the disease (for example, leprosy or yellow fever) attacked certain people and not others, creating a complex of cultural filters in an attempt to limit the transmission of the disease [15].

Many times, measures taken during an epidemic, such as burying corpses quickly in mass graves, confiscating the property of the deceased, closing markets, quarantine, etc., posed more threats to the expectations of ordinary people, than own epidemic. On the other hand, diseases (for example epidemics) were not studied epidemiologically in cultural, temporal and spatial contexts differentiated between Europe and the non-western context, and their repercussions on the population are different in these geographical and 
socio-cultural and economic places (for example, facilitating the conquest of American territories by foreigners, in the case of smallpox, and without creating this situation in the epidemic of plague in Europe) [15].

The dominant epidemiological construct for a long time, considered that certain populations were immune to the disease (for example, African blacks to malaria or yellow fever), which served as an argument to demonstrate that such populations should serve as slaves in the Americas. On the inside it looked like epidemiology, although on the outside it was about domination. On the other hand, the decline in mortality since the middle of the nineteenth century was the result of a decline in mortality from infectious diseases. But, the decline for the most part antedated the introduction of specific medical therapies, including Flemming's penicillin. allows to draw two sociological conclusions; the first is that medical care and epidemiological studies has not made a substantial contribution to mortality since the middle of the nineteenth century; The second, and more far reaching, conclusion is that today health problems are also more likely to be controlled by changing the environment than by means of medical care [22,23].

As major causes of mortality in western countries shifted from infectious to chronic illnesses around the mid 20th century, modern epidemiology developed in conjunction with a multifactorial model of disease aetiology. Within social theory, researchers have framed risk factor epidemiology in various ways. Many have pointed to the central role of epidemiological knowledge in the expansion of medical interest, reaching beyond disease to also include risk-of or risk-as disease.

This expansion has been related to medicalization processes. In many settings, epidemiological calculations still tend to have an impeccably standardized and neutral air of quantification. From the 90 s of the twentieth century, a repeated criticism referred to the main focus of epidemiology on the individual, as its unit of observation, analysis and intervention. Thus, epidemiology had little regard for the social structures and social dynamics on which individuals depend. Only a minority of studies considered the effects on health of phenomena such as racism, sexism or the destruction of the environment [24]. Although from the work of Durkheim we can observe the production of a series of investigations from the perspectives of the social and anthropological sciences [25-27]. There is no doubt that these lines of work were limited to the psychiatric field and the socalled "social deviation" until the $60 \mathrm{~s}$ and 70 s of the 20th century [20].
As an example of how the larger contextual phenomena were displaced from epidemiological study, the habit of smoking has been cited, the establishment of which, as an important risk factor, was typically considered one of the great successes of epidemiology. But, it has been pointed out that in the epidemiological study, as in related prevention strategies, smoking was typically considered a habit of individual consumers. Other parts of the scenario, such as those related to the tobacco industry, agribusiness or the social circumstances conducive to smoking, did not cause so much interest. As a result, the smoking habit decreased in the western world, especially among the most privileged, while in poorer countries it increased. Despite the success attributed to epidemiology, then many people became ill due to smoking, while health disparities worsened. One thing is to identify the risk factors for lung cancer in individuals and another to understand what changes occurred in society to lead to an epidemic of lung cancer in the 20th century [24].

This way of appropriating a concept is the one that, in some way, made it possible to circumscribe the lifestyle to certain sufferings and ways of life, excluding others. Why smoking and eating animal fats are lifestyle risks, and it is not drinking non-potable water or not eating up to the degree of chronic malnutrition? Why walking or running through the parks is part of a lifestyle and not the peasant work or that of the masons? All these behaviors are parts of lifestyles; the different thing is that in some cases the personal and social group belonging possibilities can favour the modification of their behaviors, while other subjects or groups are much more difficult due to structural economic and cultural conditions that limit or prevent the possibility of choice [20].

The concepts of lifestyle and risk merit an epistemological revision, to recover them from their current epidemiological use. They are mainly applied to the study of chronic diseases; moreover, the concept of lifestyle began to be applied as of the fifties, and especially since the sixties of the twentieth century in relation to cardiovascular diseases, in particular, referred to the habit of smoking. It was preferably applied through informative councils given by the health team to individuals or small groups to modify specific habits, and successes were shown in the modifications of said habits in certain social sectors, although not in others [20].

In this sense, it is necessary to remember that the concept of lifestyle comes from the concept "style" that was developed by the German social and historical sciences between 1880 and 1940, and applied to the different spheres of "civilization" such as art, economy, politics, thought, ideology and also everyday life. It constitutes one of the key concepts with which the 
German historicists tried to capture the cultural totalities in a general way, and of particularities that had their own structuring of meaning.

Weber's development of this concept was applied to the description of different life forms according to social classes, and articulated with psychoanalytic and phenomenological currents, it was used early for the interpretation of mental health problems and for the development of the concept "daily life" " But in addition, the historicist derivations gave rise to that the American cultural anthropology appropriated that notion with the formulation of new concepts, whose origin is in these German tendencies. But in addition this concept has strong development, although with another denomination, within the British currents of sociological and historical studies on the working class, that described a culture characterized by a whole series of features that in part were expressed in the handling of the sufferings, particularly in the doctor-patient relationship, and that through specific studies led to the proposal that the lower social classes are less oriented towards the future in relation to health, so that they are less likely to take appropriate preventive measures [20].

Several authors propose fatalism as a fundamental attitude of the British working class, but it is the global conception of class culture that establishes the data that epidemiologists found in their researches, according to which the working class duplicates in England, and in comparison with the middle and upper classes, the possibility of acquiring the tobacco habit, and also evidence much lower possibilities of abandoning it. These interpretations reduced to the lifestyle of the smoker in epidemiological studies refer to a global interpretation of the culture of the working class in which the habit of smoking, of drinking beer, of practicing physical violence, of considering to the pub as a central part of their social life, etc., are "habits" constitutive of their ways of living, of their way of being in the world, of relating to other classes, and of course with health services [20].

In the Latin American case, these proposals for lifestyles, through the concept of culture or cultural patterns, were applied more than to the working class to the study of the peasantry and the "urban marginal". These studies express this way of thinking, in which the behaviors regarding the control of the disease or the relationship between healer / patient are referred to the global characteristics of their culture. The basic points of these interpretations are that every peasant community tends to balance to try to avoid conflict, and consequently, it appears as undesirable. Avoiding conflict and ideological and economic conceptions tend to reinforce social homogeneity by generating processes (envy, witchcraft, luck function, etc.) that control and explain the situation of the community. These would lead to the development of an individualistic, distrustful and fatalistic ideology that is evident in the management of the health and disease process [20].

Therefore, the attention of epidemiology still tends to be directed towards the factors or strands of the network of causes considered "closest" to the outcome of the disease. These are typically biological agents or lifestyle factors related to the bodies and behaviors of individuals. In other words, epidemiology supports the tendencies towards blaming the victim of the disease [24-29].

For some authors, epidemiological studies often tended to "give the right answer to the wrong question", for example, by studying the cause of homelessness looking for features that differentiate homeless people from people with homes, and leaving other questions unanswered. Actually, the randomized controlled clinical trial, the 'gold standard' among epidemiological methods, did not lend itself to the study of macro-level forces. In fact, rather than achieving true objectivity, certain authors argue that traditional epidemiology assumes a political commitment to the status quo by excluding socio-economic, political and cultural issues.

Nowadays, the epidemiology molecular, fuelled by investigation of genes, genomes and biomarkers, is continuing to grow out of the work of the 1990s. However, a limited amount of epidemiologically useful information had so far been yielded. For example, in the case of cardiovascular disease, despite the identification of relevant markers, the "effect sizes per risk allele" have been modest, only explaining an extremely small increase in risk. The analysis of common multifactorial diseases such as cardiovascular disease is hindered by the interdependence of genetic and environmental factors and the difficulties that are inherent in separating the influence of individual factors [24].

If we return to analyze each of the aspects listed, we observe that although both disciplines, sociology and epidemiology, deal with social groups, epidemiology frequently describes them in terms of statistical aggregates, while anthropology works with "natural groups", or rather, the sociological approach tries not to disaggregate the groups, given that by theoretical definition they constitute a type of unity that expresses the articulation between individuals. Disaggregation of social groups into randomly selected individuals' means not assuming that these individuals define themselves as such based on the relationships established within their groups, and that most of these relationships are not random.

The disaggregation of social groups into individuals belongs to the same conception of splitting social reality 
into multiple variables, frequently lacking both disaggregated from a theoretical proposal of articulation and interrelation. This methodological way of dealing with reality often leads to produce a type of information that does not correspond to what social groups produce and reproduce with respect to the health and disease process. However, epidemiology has turned social groups into statistical aggregates, and diseases into sum of signs; this tendency would be expressed in a paradigmatic way in the DSM III and IV, codifications of psychiatric illnesses where not only does the patient disappear, but the disease is reduced to an enumeration of signs [20].

That is to say, that both the units of description and analysis (social groups), as well as the contents of those units (illnesses), are managed by epidemiology in a disaggregated, atomized and disarticulated way, at least from a socio-cultural perspective. Although epidemiology works with short historical series for understandable technical reasons, given the need to find solutions or at least explanations for immediate problems such as the emergence of acute episodes (outbreaks), it is not only for these or other similar reasons that it does not use the historical dimension, but there is a basic methodological bias [20].

From the sociological approach, both the epidemic and the non-communicable disease, in the past, have been at the service of the dominant power. Nowadays, medicine and modern epidemiology, based on the ideas of Robert Koch, have reached the capacity to control many epidemic diseases. But not all of them; for example, the inability to control malaria is due to social, intellectual and economic barriers, and not to technical ignorance. Epidemiology continues to focus on the measures of probability that establish the extent to which an event is likely to occur, rather than the dynamics through which such events occur, and the resulting lack of attention to causal social mechanisms. Although scientific knowledge has advanced dramatically in our day, medical professionals and epidemiologists are part of social systems and share their values. Thus, in certain areas of advanced North, priority is given to economic profit plans and priority is not given to the control of diseases (infectious diseases, etc.), which are now mainly found in the South. Like any other activity in social life, epidemiology cannot escape the influences of social and ideological processes $[15,30]$.

\section{Conclusion}

In short, it can be thought that the arguments of epidemiology must be qualified by sociological evidence. Epidemiology has been instrumentalized to fulfil the objectives of contributing to capitalist civilization, with its free market, and the expansion of the power of domination; but also to maintain the human work force in suitable conditions for the accumulation of capital. The epidemic disease in the past has been at the service of the dominant power. At present, although medicine and modern epidemiology have reached the capacity to control many diseases, social, intellectual and economic barriers persist.

The tension is in the difficulty to differentiate the limit between the implementation of preventive behaviors, which correspond exclusively to sanitary goals of the public health and the epidemiology, and not to other interests of diverse social order. Most of the sociology of epidemiology is still to be done, and consequently the sociological approach appears very rarely. However, the analysis and sociological evidence on the academic discipline of epidemiology can, on the one hand, qualify or complement the epidemiological arguments, and on the other hand, it favours the critical capacity of the epidemiologist to make the most of the contributions of sociology.

\section{References}

1. Epidemiology. WHO.

2. López-Moreno S, Garrido-Latorre F, HernándezAvila M (2000) Historical development of epidemiology: its formation as a scientific discipline. Salud Publica Mex 42(2).

3. De Vries R (2004) How can we help? From "sociology in" to "sociology of" bioethics. J Law Med Ethics 32(2): 279-292, 191.

4. Wheaton B (2001) The role of sociology in the study of mental health and the role of mental health in the study of sociology. J Health Soc Behav 42(3): 221-234.

5. Castro R (2016) From sociology in medicine to the sociology of collective health: contributions toward a necessary reflexivity. Salud Colect 12(1): 71-83

6. García Ballester L (2001) La búsqueda de la salud. Sanadores y enfermos en la España medieval. Barcelona: Península/HCS. 553-555.

7. Helman CG (1994) Culture, health and illness. London: Butterworth-Heinemann Ltd.

8. Rojo Pérez N, García González R (2000) Sociology and health. Reflections for action. Rev Cubana Salud Pública 26(2).

9. Malagón-Oviedo R (2017) Epidemiology, knowledge and practices: a critical analysis. Rev. Salud Pública 19(3): 416-22. 


\section{Epidemiology International Journal}

10. Turabian JL (2019) Epidemiological sociology (part one of two): "sociology in epidemiology". Sociology as an instrument of epidemiological analysis. Epidemol Int J.

11. Gieryn T (2004) Merton, Teacher. Social Studies of Science 34(6): 859-861.

12. Orozco LA, Chavarro DA (2010) Robert K. Merton (1910-2003). Science as Institution. Rev Estud Soc 37: $143-162$.

13. Nunes ED (2007) Merton and medical sociology. Hist Cienc Saude Manguinhos 14(1): 159-172.

14. Foucault M (1991) El nacimiento de la clínica. Una arqueología de la mirada médica. México: Siglo XXI Editores.

15. Campoverde N (2019) Construcción social de la salud pública como estrategia de normalización (I). Ssociologos. Blog de Sociología Y Actualidad.

16. Watts S (1997) Epidemics and History. Disease, power and imperialism. London: Yale University Press.

17. Deb Roy R (2013) Quinine, mosquitoes and empire: reassembling malaria in British India, 1890-1910. South Asian History and Culture 4(1): 65-86.

18. Worboys M (1976) The emergence of Tropical Medicine: A study in the establishment of a scientific specialty. In: G. Lemaine et al. Prerspectives on the emergence of scientific disciplines. The Hague, Netherlands: Mouton.

19. Solórzano A (1992) Sowing the seeds of neoimperialism: the Rockefeller Foundation's Yelow fever Campaing in Mexico. Int J Health Serv 22(3): 529-554.

20. Menéndez EL (1998) Lifestyles, risks and social construction. Similar concepts and meanings differents. Estudios Sociológicos.
21. Bentley JH (1966) Cross-cultural interaction and periodization in World History. Am Hist Rev 3: 749770.

22. Mackenbach JP (1996) The contribution of medical care to mortality decline: McKeown revisited. J Clin Epidemiol 49(11): 1207-1213.

23. McKeown T (1982) The role of medicine. Oxford: Basil Blackwell.

24. Wemrell M, Merlo J, Mulinari S, Hornborg AC (2016) Contemporary Epidemiology: A Review of Critical Discussions within the Discipline and a Call for Further Dialogue with Social Theory. Sociol Compass 10: 153-71.

25. Devereux, G. (1937) Institutionalized homosexuality of the Mohave Indians. Hum Bio 9: 498-527.

26. Riedel-Heller SG, Angermeyer MC (2000) Ecologic distribution of mental disorders in urban areas. Review of six decades of ecologic research in psychiatry. Psychiatr Prax 27(5): 214-20.

27. Ohrnberger J, Fichera E, Sutton M (2017) The relationship between physical and mental health: A mediation analysis. Soc Sci Med 195: 42-49.

28. Turabian JL (2019) Biopsychosocial Causality in General Medicine: Knot, Ball, and Tangle. Epidemol Int J 3(1): 000121.

29. Turabian JL, Franco BP (2017) Responses to Clinical Questions: Specialist-Based Medicine vs. Reasonable Clinic in Family Medicine. Integr J Glob Health 1: 1.

30. Briceño-León R (2003) Endemics, epidemics and fashions: the sociology of health in Latin America. Revista Española de Sociología 3: 69-85. 